\title{
Effect of 8-Week Aerobic Walking Program on Sexual Function in Women with Rheumatoid Arthritis
}

This article was published in the following Dove Press journal: International Journal of General Medicine

\author{
Sara Rezaei (D) \\ Sima Mohammadhossini (D) \\ Zohreh Karimi ${ }^{2}$ \\ Parviz Yazdanpanah ${ }^{3}$ \\ Maryam Zarei Nezhad ${ }^{4}$ \\ Hamid Reza Ghafarian Shirazi ${ }^{5}$ \\ 'Department of Nursing, School of \\ Nursing, Yasuj University of Medical \\ Sciences, Yasuj, Iran; ${ }^{2}$ Department of \\ Operating Room, School of \\ Paramedicine, Yasuj University of Medical \\ Sciences, Yasuj, Iran; ${ }^{3}$ Physical Medicine \\ and Rehabilitation, Yasuj University of \\ Medical Sciences, Yasuj, Iran; \\ ${ }^{4}$ Rheumatology, Yasuj University of \\ Medical Sciences, Yasuj, Iran; ${ }^{5}$ Social \\ Determinants of Health Research Center, \\ Yasuj University of Medical Sciences, \\ Yasuj, Iran
}

Introduction: Sexual dysfunction is a little-addressed condition in patients with rheumatoid arthritis. Aerobic exercises, including walking, can help alleviate this dysfunction. This study aimed to determine the effect of an 8-week aerobic walking program on sexual function ine patients with rheumatoid arthritis.

Methodology: This clinical trial was conducted on 51 patients with rheumatoid arthritis. At first, patients were selected through nonprobability sampling. They were then allocated into intervention and control groups using block randomization. The walking intervention was performed based on the frequency-intensity-time-type principle forg 8 consecutive weeks. Rosen's Female Sexual Function Index was used for data collection before, immediately after, and 4 weeks after the intervention. Data collected were analyzed with SPSS 22 using descriptive and inferential statistics and $95 \% \mathrm{CI}$.

Findings: Mean sexual function scores before, after, and 4 weeks after intervention were $17.66 \pm 4,22.88 \pm 4.7$, and $24.39 \pm 5.1$ in the intervention group and $17.60 \pm 4.24,17.27 \pm 4.66$, and $17.39 \pm 4.39$ in the control group, respectively. Test results showed a significant intergroup difference in mean sexual function score $(p<0.05)$.

Conclusion: Based on our results, an 8-week aerobic walking program is recommended as an effective way to improve sexual function in women with rheumatoid arthritis.

Keywords: walking, sexual function of women, rheumatoid arthritis

\section{Introduction}

Normal sexual function involves the passage of sexual activity from the stages of arousal to relaxation with no problems and with feelings of pleasure and satisfaction, ${ }^{1}$ and is impaired in some diseases like rheumatoid arthritis. ${ }^{2,3}$ Any change in each of the sexual function stages, such as decreased or increased sexual desire, inability in reaching orgasm, or pain during sexual intercourse (dyspareunia), can interfere with sexual function and results in sexual dysfunction. ${ }^{4,5}$ Sexual dysfunction has a prevalence of $46 \%-75 \%,{ }^{3,6,7}$ and is more common in women with rheumatoid arthritis compared to healthy women. ${ }^{8,9}$

Women with rheumatoid arthritis suffer from pain and limited joint range of motion. ${ }^{10}$ Also, this functional limitation has a considerable reducing effect on their quality of life. ${ }^{11}$ In fact, these symptoms can affect all aspects of life, including sexual function. ${ }^{1,12}$ Sexual dysfunction in these patients involves common symptoms, such as physical problems, impaired marital emotions and relationships, pain, fatigue, functional weakness, anxiety, negative self-image, reduced sexual desire,
Department of Operating Room, School of Paramedicine, Yasuj University of Medical Sciences, Dr Jalil Street, Yasuj, Iran

Tel/Fax +987433235138

Email zohreh.karimi@yums.ac.ir 
hormonal imbalance, and medicinal side effects. ${ }^{13,14}$ As a result, it can be said that there is a relationship between this disease and sexual dysfunction. ${ }^{2,9}$

Accordingly, health-care providers should consider suitable rehabilitation methods for patients with rheumatoid arthritis suffering from sexual dysfunction, because ensuring sexual health in these patients can be considered the first step in better dealing with the disease and improving their quality of life and survival rate. ${ }^{2}$ In this regard, many researchers have attempted to use nonpharmacological methods like aerobic exercises to reduce the disease's complications. ${ }^{15}$

Aerobic exercise is a continuous, physical exercise of constant and regular intensity that involves a greater group of muscles, with each period of training $>30$ minutes. Three to five sessions of aerobic exercise per week is required to maximize its benefits. ${ }^{16}$ Aerobic exercise includes such activities as walking, cycling, and swimming. ${ }^{16,17}$ Patients with rheumatoid arthritis who are not in the acute phase are recommended to exercise, ${ }^{15,18,19}$ including aerobic exercise. ${ }^{20,21}$

Based on the literature, aerobic, isometric, and isotonic exercises are suitable interventions for patients with rheumatoid arthritis, because they maintain not only physical health but also significantly affect psychosocial and social characteristics. ${ }^{21}$ In addition, these training programs, including walking, were designed to respond to individual needs and physical abilities of such patients, and so play an effective role in improving disease complications. ${ }^{15}$

According to the literature, walking can reduce pain and disability in patients with rheumatoid arthritis. ${ }^{22}$ As such, it is recommended as an effective exercise for patients with chronic musculoskeletal pain. ${ }^{23}$ Findings have shown that exercise, including walking, can play an effective role in the management of chronic diseases ${ }^{18}$ and reduce the cost of health care, so it can be recommended as a complementary therapy during patient care and treatment. $^{24}$

\section{Research Importance}

Although sexual dysfunction and sex-related problems in patients with rheumatoid arthritis are not life-threatening, they can have impacts on the quality of their social life, fertility, family planning, and marital issues. Therefore, it seems necessary to design programs that can affect these patients' body and mind using simple, low-cost, side effect-free, and noninvasive methods through empowerment. Since there have been no studies conducted on the effect of walking on the sexual performance of patients with rheumatoid arthritis, the present study aimed to determine the impact of an aerobic walking program for 8 weeks on the sexual function of women with rheumatoid arthritis.

\section{Methods}

The population of this clinical trial comprised all patients with rheumatoid arthritis who had been referred to the rheumatology clinic at Yasuj University of Medical Sciences in 2017. The study objective was explained to the patients by the researcher. According to assessments by a rheumatologist and the researchers, 88 patients were considered eligible to participate in the study. Of these participants, 56 were selected through convenience sampling and then randomly divided into two groups: control (A) and intervention (B). According to the factorial law of $2 !=2 \times 1$, two blocks were created: $\mathrm{AB}$ and BA. Afterward, these 56 participants were arranged usingalternative sampling and random block allocation was developed.

Inclusion criteria were definitive diagnosis of the disease by a rheumatologist, diagnosis least a year ago, nonacute episodes of the disease, being married, Rosen Female Sexual Function Index (FSFI) score $<26.5$, no other acute or chronic disease, no reproductive system disease, consuming no sexual hormone supplements affecting sexual desire, no menopause (20-50 years old), no pregnancy in the past 6 months, and not participating in physical exercise in the past 3 years. Withdrawal from the study, recurrence of an acute episode of the disease, absence for more than two sessions, divorce, pregnancy, immigration, or death were exclusion criteria. During the study, three patients from the intervention group and two from the control group were excluded due to irregular participation, disease recurrence, and immigration. Since this research population was limited and some sessions group-based, these participants could not be substituted.

Finally, data of 51 patients were collected and analyzed (details presented in Figure 1). It should be noted that prior to the start of the intervention and after a full explanation of the purpose of the study, conscious and written informed consent was obtained from all participants. In addition, confidentiality of data, voluntary participation, and right of withdrawal at any stage of this study were emphasized. The study was approved by the Ethics Committee of Yasuj University of Medical Sciences (IR. YUMS.REC.1396.133), registered in the Iranian Registry 


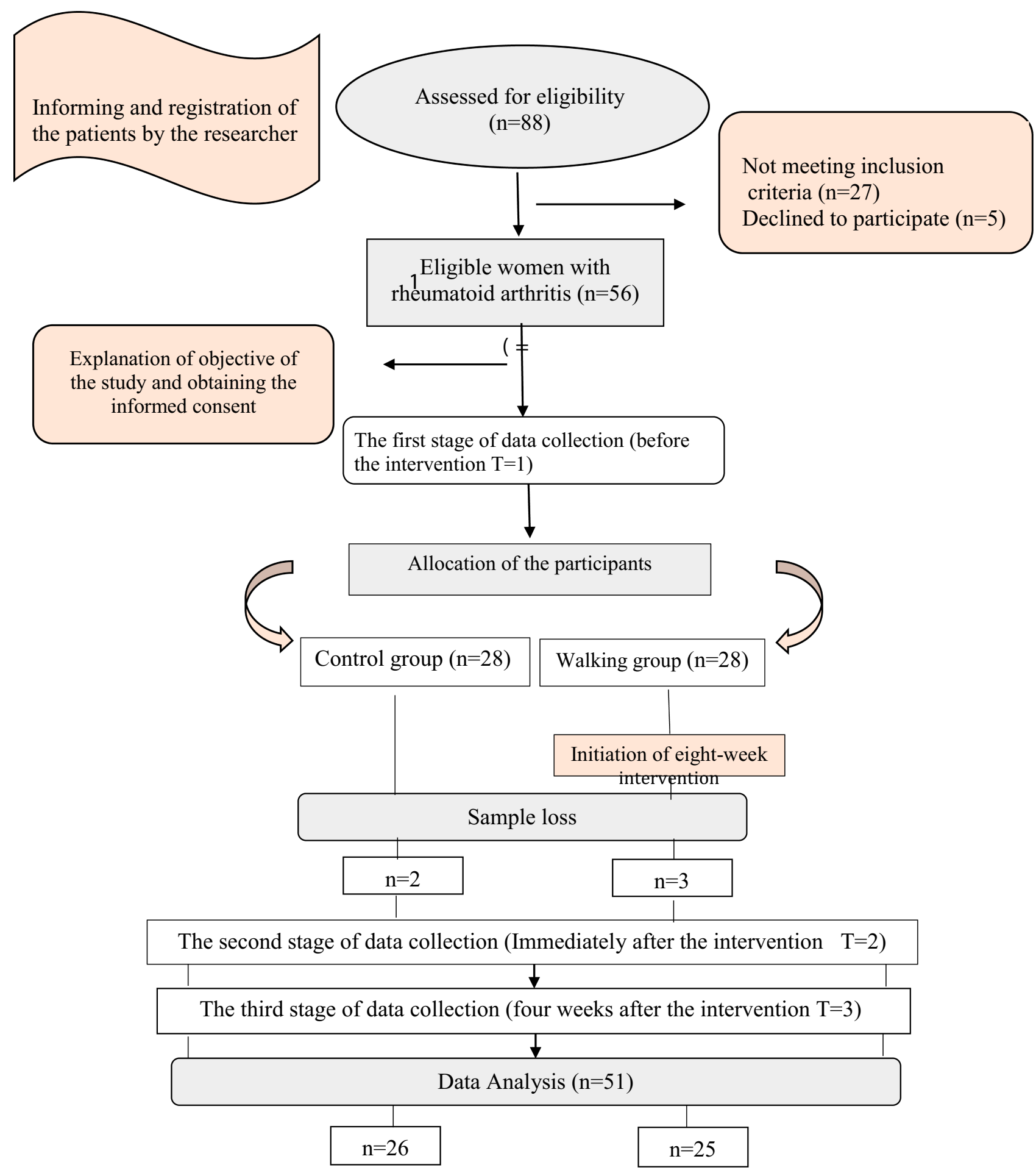

Figure I Consort flow diagram.

of Clinical Trials (IRCT20171209037802N1), and carried out in accordance with the principles of the Declaration of Helsinki.

In addition to the demographic form, the FSFI was used, which comprised 19 items and six subscales: desire, arousal, lubrication, orgasm, satisfaction, and dyspareunia.
The highest and lowest FSFI scores are 36 and 2, with a cutoff point of 26.5, respectively. This index was designed by Rosen et $\mathrm{al}^{25}$ and validity and reliability of the Persian version of the FSFI were investigated by Mohammadi et al and then approved with Cronbach's $\alpha>0.70{ }^{26}$ 
Interventions were initiated after explaining the research objectives, obtaining informed consent, and allocating participants using block randomization. The control group received only medication (routine treatment), whereas the intervention group participated in an 8-week aerobic walking program based on the criteria of the standard aerobic exercise program, as well as receiving pharmacotherapy. ${ }^{16}$ The aerobic exercise was performed basedfrequency, intensity, time, and type. In the intervention group, the walking-exercise protocol included 30 sessions of walking for eight weeks (five sessions in the first and second weeks, four sessions in the third and fourth weeks, and three sessions in weeks five to eights). The time and content of the walking program varied during the 8 -week period, with walking intensity and duration increased and decreased over time based on the patient's condition and ability, respectively. Therefore, exercise duration was reduced from $60 \mathrm{~min}-$ utes to 30 minutes and exercise intensity increased from $60 \%$ to $70 \%$ from the first to the eighth weeks.

All walking sessions were based on Table 1 plusinitial control, warm-up of light-moderate physical activity, main walking session, cool-down similar to warm-up, and final control. It should be noted that the necessary training was conducted by a physical education expert who was present in the briefing and the first practice session. First-week exercises were performed as a group in the sports hall of Yasuj University of Medical Sciences, and then to monitor the process of correct intervention, one to two sessions per week were performed as group sessions in the hall. The FSFIwas completed by the participants before the intervention (first time), immediately after the intervention (second time), and 4 weeks after the intervention following two to three episodes of sexual intercourses (third time), and afterward the data were collected by the researchers. Data collected were analyzed using descriptive and inferential statistics in SPSS 22. Qualitative and quantitative demographic data were analyzed using independent $t$-tests and $\chi^{2}$ tests. Distribution of sexual function scores was analyzed with the Kolmogorov-Smirnov test. The significance level was set at $p<0.05$ with CI $95 \%$.

\section{Results}

A total of 51 women with rheumatoid arthritis participated in the study. According to the results of statistical tests (Table 2), there was no significant intergroup difference in demographic data $(p>0.05)$. There was no significant intergroup difference in terms of sexual function score before the intervention $(p>0.05)$ either. Mean scores of sexual function before the intervention, immediately after the intervention, and 4 weeks after the intervention were $17.66 \pm 4.00,22.88 \pm 4.70$, and $24.39 \pm 5.10$ in the intervention groupand $17.60 \pm 4.24,17.27 \pm 4.66$, and $17.39 \pm 4.39$ in the control group, respectively.

As shown in Table 3, there was a significant intergroup difference in mean scores of sexual function and subscales immediately after the intervention and 4 weeks after the intervention $(p=0.0001)$.Intragroup comparison of mean scores of sexual function and subscales in the intervention group showed a significant increase immediately after the intervention and 4 weeks after the intervention $(p<0.05)$ compared to before the intervention (Table 4). However, there was no significant difference in desire or lubrication between immediately after the intervention and 4 weeks after. In the control group, the intragroup comparison indicated no significant difference in mean scores of sexual function and subscales among before intervention (time 1), immediately after intervention (time 2), and 4 weeks after intervention (time 3).

\section{Discussion}

The current study was conducted to determine the effect of an 8-week aerobic walking program on sexual function inwomen with rheumatoid arthritis. The results showed the effectiveness of walking in improving sexual function in these patients. Many studies have examined the effect of exercise on improving sexual function, some of which

Table I Eight-week aerobic walking program

\begin{tabular}{|l|l|l|l|l|l|l|}
\hline Weeks & $\begin{array}{l}\text { Warmup } \\
\text { (minutes) }\end{array}$ & $\begin{array}{l}\text { Walking } \\
\text { (minutes) }\end{array}$ & $\begin{array}{l}\text { Cool-down } \\
\text { (minutes) }\end{array}$ & $\begin{array}{l}\text { Total time } \\
\text { (minutes) }\end{array}$ & Intensity & $\begin{array}{l}\text { Number of } \\
\text { sessions per week }\end{array}$ \\
\hline Ist and 2nd & 5 & 40 & 5 & 50 & 60 & 5 \\
3rd and 4th & 5 & 35 & 5 & 45 & 60 & 4 \\
5th and 6th & 5 & 30 & 5 & 40 & 70 & 3 \\
7th and 8th & 5 & 25 & 5 & 35 & 70 & 3 \\
\hline
\end{tabular}


Table 2 Demographic characteristics of intervention and control groups

\begin{tabular}{|c|c|c|c|c|c|c|}
\hline & \multirow[t]{2}{*}{ Group } & \multirow[t]{2}{*}{ Mean \pm SD } & \multirow{2}{*}{\multicolumn{2}{|c|}{ n (\%) }} & \multicolumn{2}{|c|}{ Statistics } \\
\hline & & & & & $p$-value & $t$-test \\
\hline Age (years) & Intervention & $40.4 \pm 6.5$ & \multicolumn{2}{|l|}{ - } & 0.589 & Independent-sample $t$-test \\
\hline \multirow[t]{2}{*}{ Weight (kg) } & Intervention & $75.24 \pm 12.8$ & - & & \multirow[t]{2}{*}{0.783} & \multirow[t]{2}{*}{ Independent-sample $t$-test } \\
\hline & Control & $74.15 \pm 14.9$ & - & & & \\
\hline \multirow[t]{2}{*}{ Time since diagnosis (years) } & Intervention & $5.7 \pm 5.8$ & - & & \multirow[t]{2}{*}{0.231} & \multirow[t]{2}{*}{ Independent-sample $t$-test } \\
\hline & Control & $7.57 \pm 4.8$ & - & & & \\
\hline \multirow[t]{2}{*}{ Onset age (years) } & Intervention & $34.8 \pm 7.4$ & \multirow{2}{*}{\multicolumn{2}{|c|}{-}} & 0.729 & Independent-sample $t$-test \\
\hline & Control & $33.68 \pm 8.62$ & & & & \\
\hline \multirow[t]{4}{*}{ Employment status } & Intervention & - & Housewife & $14(56)$ & \multirow[t]{4}{*}{0.057} & \multirow[t]{4}{*}{$\chi^{2}$} \\
\hline & & & Employer or student & II (44) & & \\
\hline & Control & - & Housewife & $21(80.8)$ & & \\
\hline & & & Employer or student & $5(16.2)$ & & \\
\hline \multirow[t]{4}{*}{ Domicile } & Intervention & - & City & $22(88)$ & \multirow[t]{4}{*}{0.057} & \multirow[t]{4}{*}{$\chi^{2}$} \\
\hline & & & Village & $3(12)$ & & \\
\hline & Control & - & City & $17(65.4)$ & & \\
\hline & & & Village & $9(34.6)$ & & \\
\hline \multirow[t]{6}{*}{ Type of birth } & Intervention & - & C-section & $7(28)$ & \multirow[t]{6}{*}{0.225} & \multirow[t]{6}{*}{$\chi^{2}$} \\
\hline & & & Vaginal & $16(64)$ & & \\
\hline & & & both & $2(8)$ & & \\
\hline & Control & - & C-section & $3(11.5)$ & & \\
\hline & & & Vaginal & $18(69.2)$ & & \\
\hline & & & both & $5(19.2)$ & & \\
\hline \multirow[t]{4}{*}{ Fatigue } & Intervention & & With & $21(84)$ & \multirow[t]{4}{*}{0.34} & \multirow[t]{4}{*}{$\chi^{2}$} \\
\hline & & & Without & $4(16)$ & & \\
\hline & Control & & With & $26(100)$ & & \\
\hline & & & Without & 0 & & \\
\hline \multirow[t]{4}{*}{ Morning stiffness } & Intervention & & With & $22(88)$ & \multirow[t]{4}{*}{0.959} & $\chi^{2}$ \\
\hline & & & Without & $3(12)$ & & \\
\hline & Control & & With & $23(88.5)$ & & \\
\hline & & & Without & $3(5 / 11)$ & & \\
\hline
\end{tabular}

have indicated a positive relationship between sexual function and exercise and physical activity. ${ }^{27}$

Lutfey et al showed that women with moderatehigh physical activity also had more sexual activity. ${ }^{28}$ Dabrowska et al concluded that there was a positive relationship between high physical activity and female sexual function before menopause. ${ }^{29}$ In addition, Dhikav et al found that yoga was an efficient exercise to improve all areas of sexual function in adult women. ${ }^{30}$ Moreover, Cabra et al showed that physical activity had a positive effect on the sexual performance of middle-aged women, ${ }^{27}$ which is consistent with the results of the present study. Although inconsistent with this study's results, Kim et al reported the effectiveness of a 12-week yoga session on improving sexual arousal and lubrication in women with metabolic syndrome and observed no significant difference between the intervention and control groups in sexual function scores. ${ }^{31}$

Aerobic exercise involves continuous and often rhythmic muscle motions, which increase circulation and metabolic need for oxygen intake and improve cardiovascular 
Table 3 Comparison of Sexual Function Between the Intervention and Control Groups Before Intervention (Time I), Immediately After Intervention (Time 2), and Four Weeks After Intervention (Time 3)

\begin{tabular}{|c|c|c|c|c|c|}
\hline & Time & Group & $n$ & Mean \pm SD & Test \\
\hline \multirow{6}{*}{$\begin{array}{l}\text { Sexual } \\
\text { performance } \\
\text { score }\end{array}$} & \multirow[t]{2}{*}{ First } & Intervention & 25 & $17.66 \pm 4.00$ & $t=0.05$ \\
\hline & & Control & 26 & $17.6 \pm 4.24$ & $p=0.9$ \\
\hline & \multirow[t]{2}{*}{ Second } & Intervention & 25 & $22.88 \pm 4.7$ & $t=0.05$ \\
\hline & & Control & 26 & $17.27 \pm 4.66$ & $p=0.9$ \\
\hline & \multirow[t]{2}{*}{ Third } & Intervention & 25 & $17.39 \pm 4.39$ & $t=0.05$ \\
\hline & & Control & 26 & $17.39 \pm 4.39$ & $p=0.9$ \\
\hline
\end{tabular}

Table 4 Pairwise comparison of sexual function scores between the intervention and control groups before intervention (time I), immediately after intervention (time 2 ), and 4 weeks after intervention (time 3)

\begin{tabular}{|l|l|l|}
\hline & Time 2 & Time 3 \\
\hline Time I & $\begin{array}{l}\text { Mean difference 5.216, } \\
p=0.0001\end{array}$ & $\begin{array}{l}\text { Mean ifference 6.728, } \\
p=0.0001\end{array}$ \\
\hline Time 2 & - & $\begin{array}{l}\text { Mean difference I.5I2, } \\
p=0.000 \mathrm{I}\end{array}$ \\
\hline
\end{tabular}

condition. ${ }^{17}$ In fact, regular physical exercises improve the circulatory system by strengthening the heart muscles and increasing blood volume. In other words, not only the heart muscles and valves are strengthened but blood volume is also improved. As a result, the heart can pump more blood to the muscles and other organs of the body with each heartbeat. ${ }^{32}$ Similarly to the mechanism of orgasm in a good sexual relationship, aerobic exercises increase the secretion of oxytocin and endorphin, which help in reducing tension and body fat, refreshing the body; and enhancingsense of happiness, strength, vitality, selfconfidence, and well-being. Regular exercise also increases blood flow in the genital area and prepares people for sexual activity. ${ }^{33}$

The results showed a significant difference in sexual function scores and subscales. Physical activity before intercourse significantly improves sexual desire. ${ }^{34}$ Moreover, regular sexual activity considerably improves sexual orgasm; however, neither regular sexual activitys nor physical exercise resulted in major changes in sexual satisfaction. ${ }^{34}$ Halis et al showed that Pilates improved sexual function in healthy women. ${ }^{35}$ Accordingly, it seems that walking can moderate behavioral and mood disorders caused by sexual dysfunction and improve some complications of sexual dysfunction, such as reduced sexual desire, orgasmic dysfunction, and reduced sexual satisfaction. Moreover, walking can also enhance sexual and marital satisfaction by strengthening the circulatory system, cardiovascular system, respiratory capacity, and muscles and regulating and coordinating endocrine glands and effective hormones in sexual activities, such as oxytocin, endorphins, dopamine, prolactin, and serotonin. In other words, it can considerably improve all the mechanisms effective in healthy and desirable sexual activity.

This study was associated with some limitations, including a relatively limited population of patients with rheumatoid arthritis, which became more limited due to the inclusion criteria; differences in personality, values, and family relations, specifically between partners, unsupported psychological changes, and irregular participation of some participants, which was overcome by encouraging regular presence or reholding sessions where the participant wanted; and also cultural issues and feelings of shame, which acted as barriers against investigating sexual function.

\section{Conclusion}

It was found that the 8 -week aerobic walking program improved sexual function in women with rheumatoid arthritis. Due to limited medicinal treatment to improve sexual function in women with rheumatoid arthritis, walking grew popular and was accepted by the patients, due low cost, simplicity, and nonaggression. Therefore, patients and their families can take an enormous step in coping with sexual relationships issues by undertaking these activities and introducing them to their lifestyle. Considering that rheumatoid arthritis can also affect young people and the institutionalization of correct selfcare habits and behaviors being easier in this age range, performing such exercises is a good solution to improve sexual function.

\section{Data-Sharing Statement}

All data requests should be submitted to the corresponding author for consideration. Access to anonymized data may be granted following review.

\section{Acknowledgments}

All patients with rheumatoid arthritis and those who helped us in conducting this study are thanked. The financial support from the Research and Technology Deputy of Yasuj University of Medical Sciences is also appreciated. 


\section{Disclosure}

The authors report no conflicts of interest in this work.

\section{References}

1. Tristano A. Impact of rheumatoid arthritis on sexual function. World J Orthop. 2014;5(2):107. doi:10.5312/wjo.v5.i2.107

2. Lin M-C, Lu M-C, Livneh H, Lai N-S, Guo H-R, Tsai T-Y. Factors associated with sexual dysfunction in Taiwanese females with rheumatoid arthritis. BMC Women's Health. 2017;17(1):12. doi:10.1186/ s12905-017-0363-5

3. Coskun B, Coskun BN, Atis G, Ergenekon E, Dilek K. Evaluation of sexual function in women with rheumatoid arthritis. Urol J. 2014;10 (4):1081-1087.

4. de Almeida PHTQ, de Castro Ferreira C, Kurizky PS, Muniz LF, da Mota LMH. How the rheumatologist can guide the patient with rheumatoid arthritis on sexual function. Revista Brasileira De Reumatologia (English Edition). 2015;55(5):458-463. doi:10.1016/j. rbre.2014.08.008

5. American Psychiatric Association. Diagnostic and Statistical Manual of Mental Disorders (DSM-5). 5th ed. Washington: American Psychiatricp Publishing; 2013:423-424.

6. Nasr MM, El-Shafey AM. Sexual performance in rheumatoid arthritis patients-An unnoticed problem. Egypt Rheumatol. 2013;35 (4):201-205. doi:10.1016/j.ejr.2013.07.001

7. El Miedany Y, El Gaafary M, El Aroussy N, Youssef S, Ahmed I. Sexual dysfunction in rheumatoid arthritis patients: arthritis and beyond. Clin Rheumatol. 2012;31(4):601-606. doi:10.1007/s10067011-1891-2

8. Costa TF, Silva CR, Muniz LF, Mota L. Prevalence of sexual dysfunction among female patients followed in a Brasília Cohort of early rheumatoid arthritis. Rev Bras Reumatol. 2015;55(2):123-132. doi:10.1016/j.rbr.2014.10.006

9. Alia F, Rim BS, Miladi S, et al. Comparison of sexual function in Tunisian women with rheumatoid arthritis and healthy controls. Clin Rheumatol. 2019;38(12):3361-3365. doi:10.1007/s10067-019-047 26-8

10. vanberlo WT, van de Wiel HB, Taal E, Rasker JJ, Schultz WCW, van Rijswijk MH. Sexual functioning of people with rheumatoid arthritis: a multicenter study. Clin Rheumatol. 2007;26(1):30-38. doi:10.1007/ s10067-006-0216-3

11. Cho S-K, Kim D, Jun J-B, Bae S-C, Sung Y-K. Factors influencing quality of life (QOL) for Korean patients with rheumatoid arthritis (RA). Rheumatol Int. 2013;33(1):93-102. doi:10.1007/s00296-0112352-6

12. Reese JB, Somers TJ, Keefe FJ, Mosley-Williams A, Lumley MA. Pain and functioning of rheumatoid arthritis patients based on marital status: is a distressed marriage preferable to no marriage? J Pain. 2010;11(10):958-964. doi:10.1016/j.jpain.2010.01.003

13. Perdriger A, Solano C, Gossec L. Why should rheumatologists evaluate the impact of rheumatoid arthritis on sexuality? Joint Bone Spine. 2010;77(77):493-495. doi:10.1016/j.jbspin.2010.07.005

14. Yilmaz H, Polat HAD, Yilmaz SD, et al. Evaluation of sexual dysfunction in women with rheumatoid arthritis: a controlled study. J Sex Med. 2012;9(10):2664-2670. doi:10.1111/j.1743-6109.2012. 02882.x

15. Metsios GS, Stavropoulos-Kalinoglou A, van Zanten JJV, et al. Individualised exercise improves endothelial function in patients with rheumatoid arthritis. Ann Rheum Dis. 2014;73(4):748-751. doi:10.1136/annrheumdis-2013-203291

16. Robert P, Jeffrey G. Theraputic exercise. In: David X, Cifu M, editors. Braddom's Physical Medicine and Rehabilitation. 5. 5th ed Canada: Working toghether togrow libraries in developing countries; 2016:321-346.
17. Stubbe J, De Moor M, Boomsma D, De Geus E. The association between exercise participation and well-being: a co-twin study. Prev Med. 2007;44(2):148-152. doi:10.1016/j.ypmed.2006.09.002

18. Metsios GS, Kitas GD. Physical activity, exercise and rheumatoid arthritis: effectiveness, mechanisms and implementation. Best Pract Res Clin Rheumatol. 2018;32(5):669-682. doi:10.1016/j.berh.2019.03.013

19. Plasqui G. The role of physical activity in rheumatoid arthritis. Physiol Behav. 2008;94(2):270-275. doi:10.1016/j.physbeh.2007.12.012

20. Jahanbin I, Moghadam MH, Nazarinia MA, Ghodsbin F, Bagheri Z, Ashraf AR. The effect of conditioning exercise on the health status and pain in patients with rheumatoid arthritis: a randomized controlled clinical trial. Int J Commun Based Nurs Midwifery. 2014;2 (3): 169 .

21. de Jong Z, Munneke M, Kroon HM, et al. Long-term follow-up of a high-intensity exercise program in patients with rheumatoid arthritis. Clin Rheumatol. 2009;28(6):663-671. doi:10.1007/s10067-009$1125-\mathrm{z}$

22. Roddy E, Zhang W, Doherty M. Aerobic walking or strengthening exercise for osteoarthritis of the knee? A systematic review. Ann Rheum Dis. 2005;64(4):544-548. doi:10.1136/ard.2004.028746

23. O'Connor SR, Tully MA, Ryan B, et al. Walking exercise for chronic musculoskeletal pain: systematic review and meta-analysis. Arch Phys Med Rehabil. 2015;96(4):724-34. e3. doi:10.1016/j. apmr.2014.12.003

24. Hurley MV, Walsh NE, Mitchell H, Nicholas J, Patel A. Long-term outcomes and costs of an integrated rehabilitation program for chronic knee pain: a pragmatic, cluster randomized, controlled trial. Arthritis Care Res (Hoboken). 2012;64(2):238-247. doi:10.1002/ acr.20642

25. Rosen C, Brown J, Heiman S, et al. The Female Sexual Function Index (FSFI): a multidimensional self-report instrument for the assessment of female sexual function. $J$ Sex Marital Ther. 2000;26 (2):191-208. doi:10.1080/009262300278597

26. Mohammadi K, Heydari M, Faghihzadeh S. Validity of persian version of female sexual function index-FSFI. Payesh. 2008;7 (2):269-278. [in Persian].

27. Cabral PU, Canario AC, Spyrides MH, et al. Physical activity and sexual function in middle-aged women. Rev Assoc Med Bras. 2014;60(1):47-52. doi:10.1590/1806-9282.60.01.011

28. Lutfey KE, Link CL, Rosen RC, Wiegel M, McKinlay JB. Prevalence and correlates of sexual activity and function in women: results from the Boston Area Community Health (BACH) Survey. Arch Sex Behav. 2009;38(4):514-527. doi:10.1007/s10508-007-9290-0

29. Dąbrowska J, Drosdzol A, Skrzypulec V, Plinta R. Physical activity and sexuality in perimenopausal women. Eur J Contracept Reprod Health Care. 2010;15(6):423-432. doi:10.3109/13625187.2010.529968

30. Dhikav V, Karmarkar G, Gupta R, et al. Yoga in female sexual functions. J Sex Med. 2010;7(2pt2):964-970. doi:10.1111/j.17436109.2009.01580.x

31. Kim H-N, Ryu J, Kim K-S, Song S-W. Effects of yoga on sexual function in women with metabolic syndrome: a randomized controlled trial. $J \mathrm{Sex}$ Med. 2013;10(11):2741-2751. doi:10.1111/jsm.12283

32. Moodi H, Chiasi F, Afshar M, Akbari A, Harati H, Moodi M. The impact of a plyometric and aerobic exercises on chest expansion and lung volume in high school students. Shahrekord Univ Med Sci. 2009;11(2):30-38.

33. Herbenick D, Fortenberry JD. Exercise-induced orgasm and pleasure among women. Sexual Relationship Ther. 2011;26(4):373-388. doi:10.1080/14681994.2011.647902

34. Lorenz TA, Meston CM. Exercise improves sexual function in women taking antidepressants: results from a randomized crossover trial. Depress Anxiety. 2014;31(3):188-195. doi:10.1002/da.22208

35. Halis F, Yildirim P, Kocaaslan R, Cecen K, Gokce A. Pilates for better sex: changes in sexual functioning in healthy Turkish women after Pilates exercise. J Sex Marital Ther. 2016;42(4):302-308. doi:10.1080/0092623X.2015.1033576 


\section{Publish your work in this journal}

The International Journal of General Medicine is an international, peer-reviewed open-access journal that focuses on general and internal medicine, pathogenesis, epidemiology, diagnosis, monitoring and treatment protocols. The journal is characterized by the rapid reporting of reviews, original research and clinical studies across all disease areas. The manuscript management system is completely online and includes a very quick and fair peer-review system, which is all easy to use. Visit http://www.dovepress.com/ testimonials.php to read real quotes from published authors.

Submit your manuscript here: https://www.dovepress.com/international-journal-of-general-medicine-journal 